\title{
Antiophidian properties of plant extracts against Lachesis muta venom
}

\author{
De Paula RC (1), Sanchez EF (2), Costa TR (3), Martins CHG (4), Pereira PS (5), \\ Lourenço MV (5), Soares AM (3), Fuly AL (1)
}

(1) Department of Cell Biology, Institute of Biology, Fluminense Federal University, Niterói, Rio de Janeiro State, Brazil; (2) Center for Research and Development, Ezequiel Dias Foundation, Belo Horizonte, Minas Gerais State, Brazil; (3) Department of Clinical, Toxicological and Bromatological Analysis, School of Pharmaceutical Sciences, University of São Paulo, Ribeirão Preto, São Paulo State, Brazil; (4) Research Group on Natural Products, Laboratory of Applied Microbiology, University of Franca, Franca, São Paulo State, Brazil; (5) Biotechnology Unit, University of Ribeirão Preto, Ribeirão Preto, São Paulo State, Brazil.

ABSTRACT: Snakebites comprise a serious health problem in several countries due to their global incidence, which exceeds 2.5 million per year, and the elevated number of victim fatalities. To counteract envenomations, antivenoms have been used regularly for more than a century. Apart from side effects including anaphylactic reactions, antivenoms are not able to efficiently neutralize local tissue damage, which contributes to increasing the severity and morbidity observed in patients. This fact, in turn, may be responsible for economic hardship, particularly in rural populations of developing countries. In the present work, we evaluated the antiophidian properties of 12 Brazilian plant extracts against the hemolytic, coagulant, hemorrhagic and proteolytic effects of Lachesis muta venom. Taken together, our data revealed that most of these aqueous products were capable of inhibiting those activities at different levels, except for Sapindus saponaria extract. In contrast, Stryphnodendron barbatiman extract completely neutralized all the analyzed biological activities. Thus, we may conclude that Brazilian flora may also be useful against $L$. muta accidents.

KEY WORDS: snake venom, Lachesis muta, plant extract, antivenom, biological activities.

CONFLICTS OF INTEREST: There is no conflict.

FINANCIAL SOURCE: FAPERJ, FAPESP, CNPq, CAPES and IFS (grant F/4571-1).

\section{CORRESPONDENCE TO:}

ANDRÉ LOPES FULY, Departamento de Biologia Celular e Molecular, Instituto de Biologia, Universidade Federal Fluminense, Niterói, RJ, 24210-150, Brasil. Phone: + 55212629 2294. Fax: + 55212629 2376. Email: andfuly@vm.uff.br. 


\section{INTRODUCTION}

Snake venoms are a complex mixture of components that affect a wide range of tissues and organs. We may consider the main active ones to be phospholipases $A_{2}$ enzymes, metallo- and serine proteases, phosphodiesterases, myotoxins, lectins, Lamino acid oxidases, disintegrins and neurotoxins, which are responsible for hemorrhage, necrosis, edema, blood clotting, hypotension and neurotoxicity effects in victims (1). In Brazil, Bothrops, Crotalus, Lachesis and Micrurus genus are responsible for, respectively, 90, 7, 2 and $0.5 \%$ of the accidents. But, although the accidents caused by Lachesis are rare, the incidence of death (also denominated lethality or fatality index) should be considered (2).

Envenomation by snakes is often treated by parenteral administration of antiophidian serum (antivenoms) obtained from hyperimmunized equine serum. This serum therapy efficiently neutralizes the systemic toxic effects, thus preventing victim fatalities. However, antivenoms present some disadvantages. They can induce adverse reactions ranging from mild symptoms to serious ones and they do not neutralize the local tissue damage (3). Thus, it is important to search for new venom inhibitors, whether synthetic or from a natural source, to complement the traditional serum therapy. Hence, the aim of this work was to evaluate the antiophidian properties of twelve aqueous plant extracts from Brazilian flora against biological effects caused by L. muta snake venom.

\section{MATERIALS AND METHODS}

\section{Venom and Animals}

Lachesis muta snake venom was kindly supplied by the Ezequiel Dias Foundation, Belo Horizonte, Minas Gerais state, Brazil, vacuum dried and stored at $-20^{\circ} \mathrm{C}$ until experiments. Male Swiss Wistar mice (18-20 g) were obtained from the Center of Laboratory Animals (NAL) of the Fluminense Federal University (UFF).

\section{Plant Extracts}

The number of columns, which appears in parenthesis, represents the plant extracts in the graphs displayed in the Results section. Leaves, stems and roots of Eclipta alba (column 1), Mandevilla velutina (column 2), Mikania glomerata (column 3), Jatropha ellyptica (leaves, column 4), Jatropha ellyptica (stems, column 5), Miconia fallax (column 6), Miconia albicans (column 7), Miconia sellowiana (column 8), 
Stryphnodendron barbatiman (column 9), Tibouchina stenocarpa (column 10), Casearia sylvestris (column 11) and Sapindus saponaria (column 12) were collected from the Biotechnology Unit of the University of Ribeirão Preto (UNAERP), São Paulo state, Brazil. A voucher specimen of each plant has been deposited at UNAERP and authenticated by Professor Hermógenes de Freitas Leitão Filho of the Institute of Biology, State University of Campinas (UNICAMP). Plant extracts were prepared according to Maiorano et al. (4) and further dissolved in physiological saline solution yielding aqueous extracts.

\section{Inhibition of the Venom}

For inhibition experiments, a fixed amount of $L$. muta snake venom was mixed with varying amounts of plant extracts to obtain two venom:plant ratios (w/w), 1:10 and 1:20. Then, the mixture was incubated for 30 minutes at room temperature (r.t.), after which the biological assays were performed.

\section{Phospholipase $A_{2}\left(P_{2}\right)$ Activity}

$\mathrm{PLA}_{2}$ activity was determined by the indirect hemolytic test using human erythrocytes and hen's egg yolk emulsion as substrate (5). One minimum indirect hemolytic dose (MIHD) was defined as the amount of $L$. muta venom $(\mu \mathrm{g} / \mathrm{mL})$ able to produce 70 $80 \%$ hemolysis. To verify the inhibitory action of plant extracts, they were preincubated with one MIHD and the hemolytic assay was performed. The maximal effect (100\% hemolysis) was obtained after lysing erythrocytes with distilled water to constitute the control.

\section{Clotting Activity}

A normal pool of human plasma from healthy volunteers was mixed with L. muta crude venom and clotting experiments were performed in an Organon Teknika BE Coagulator $1 \circledR$ (Germany) (6). The amount of venom $(\mu \mathrm{g} / \mathrm{mL})$ that clots plasma in 60 seconds was denoted as the minimum coagulant dose (MCD). The anticlotting effect of plant extracts was determined against one MCD. Plant extracts were used as control instead of venom. 


\section{Hemorrhagic Activity}

Hemorrhagic lesions produced by L. muta venom were quantified by intradermally injecting samples into abdominal skin of mice two hours before the animals were euthanized according to the UFF Institutional Committee for Ethics in Animal Experimentation (7). Then, abdominal skin was removed, stretched and the site of injection analyzed. One minimum hemorrhagic dose (MHD) was defined as the amount of venom $(\mu \mathrm{g} / \mathrm{g})$ that produced a hemorrhagic halo of $10 \mathrm{~mm}$. Hemorrhagic activity was expressed by the means (in $\mathrm{mm}$ ) of the hemorrhagic halos induced by $L$. muta venom in the absence or presence of plant extracts. Negative control experiments were performed by injecting saline, in parallel.

\section{Proteolytic Activity}

Proteolytic activity was determined according to the method of Garcia et al. (8) using azocasein as substrate $(0.2 \% \mathrm{w} / \mathrm{v}$, in $20 \mathrm{M}$ Tris- $\mathrm{HCl}, 8 \mathrm{mM} \mathrm{CaCl}, \mathrm{pH} 8.8)$ in the presence or absence of plant extracts. One minimum proteolytic dose (MPD) was defined as the amount of venom $(\mu \mathrm{g} / \mathrm{mL})$ able to produce a variation of 0.2 at A405 $\mathrm{nm}$.

\section{Ethics Committee}

The experiments were approved by the UFF Institutional Committee for Ethics in Animal Experimentation and are in accordance with the guidelines of the Brazilian College for Animal Experimentation (COBEA).

\section{Statistical Analysis}

Results are expressed as means \pm SD obtained with the indicated number of animals or experiments performed. The statistical significance of differences among experimental groups was evaluated using the ANOVA test and $p$ values less than 0.05 were considered statistically significant.

\section{RESULTS}

A previous study found that $L$. muta venom presented phospholipase $A_{2}$ (indirect hemolytic activity), hemorrhagic and proteolytic activities and also induced blood clotting (9). Herein, we evaluated the ability of different plant extracts to neutralize those related biological activities of $L$. muta crude venom. 


\section{Antihemolytic and Anticlotting Effects}

As shown in Figure 1, plant extracts were able to inhibit the indirect hemolytic (Panel A) and clotting (Panel B) activities caused by L. muta venom (12 $\mu \mathrm{g} / \mathrm{mL}$ and 15 $\mu \mathrm{g} / \mathrm{mL}$ ), but with different potencies. The venom concentrations used above represent the MIHD and MCD, respectively. However, the extracts of $E$. alba (column 1), M. velutina (column 2), M. fallax (column 6), M. albicans (column 7), S. barbatiman (column 9) and T. stenocarpa (column10) inhibited the indirect hemolytic activity (100\%), in contrast to S. saponaria (column 12) which did not neutralize this effect. Meanwhile, E. alba (column 1), M. velutina (column 2), S. barbatiman (column 9) and T. stenocarpa (column 10) fully inhibited coagulation of L. muta (100\%), since no clotting was observed throughout ten minutes of observation. However, $M$. glomerata (column 3), J. ellyptica (column 4), J. ellyptica (column 5), M. albicans (column 7), M. sellowiana (column 8), S. barbatiman (column 9), T. stenocarpa (column 10), C. sylvestris (column 11) and again S. saponaria (column 12) did not counteract the clotting effect of $L$. muta venom. The $M$. fallax extract (column 6 ) was able to delay clotting fourfold (at 1:20 venom:plant ratio) when compared with venom. None of the plant extracts alone produced hemolysis or induced blood clotting (data not shown). 

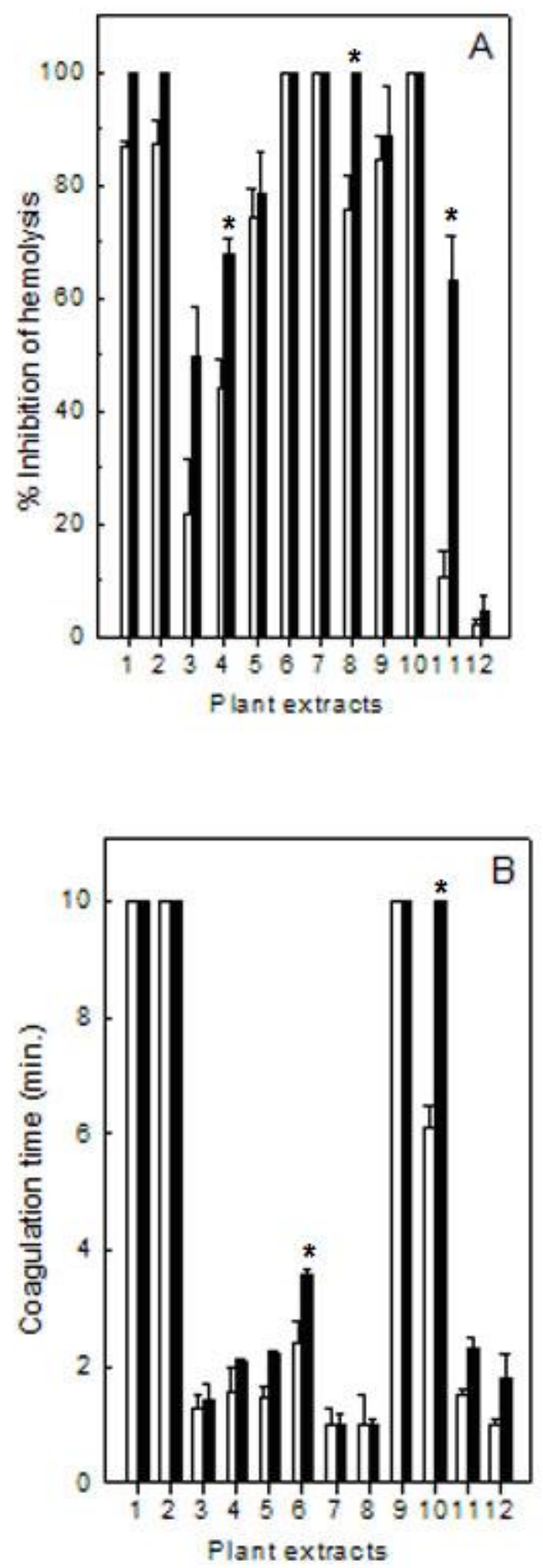

Figure 1. Inhibition of hemolytic (Panel A) or blood clotting (Panel B) activities of $L$. muta crude venom by plant extracts at 1:10 (white column) or 1:20 (black column) venom:plant ratio $(w / w)$. Data are expressed as means \pm SD of three individual experiments $(n=3)$.

* Significance level $(p<0.05)$ when compared to the white column. 


\section{Antihemorrhagic and Antiproteolytic Effects}

The effects of aqueous extracts on hemorrhagic (Figure 2A) and proteolytic (Figure 2B) activities induced by L. muta venom were also analyzed. As observed in Figure $2 \mathrm{~A}$, the extracts of M. glomerata (column 3) and S. saponaria (column 12) did not counteract $L$. muta venom-induced hemorrhage $(12.5 \mu \mathrm{g} / \mathrm{g})$. In contrast, all of the other plant extracts (J. ellyptica, column 4; J. ellyptica, column 5; M. fallax, column 6; M. sellowiana, column 8; S. barbatiman, column 9 and T. stenocarpa, column 10) did neutralize such lesions induced by $L$. muta venom and produced inhibition of around $100 \%$ (Figure 2A).

It is worth noting that $S$. barbatiman extract (column 9) produced $100 \%$ inhibition of a three-fold MHD (30 $\mu \mathrm{g} / \mathrm{g})$ of $L$. muta (data not shown). In parallel, plant extracts also inhibited one MPD of $L$. muta venom $(10 \mu \mathrm{g} / \mathrm{mL}$ ) with different potencies (Figure $2 \mathrm{~B}$ ). As shown, the extracts of $M$. velutina (column 2) and M. glomerata (column 3 ) presented the lowest inhibitory effect (60 and $65 \%$ for 1:10 venom:plant ratio; 85\% and $65 \%$ for $1: 20$ ) while $S$. sapindus (column 12) was not capable of inhibiting this phenomenon. The other plant extracts - J. ellyptica (column 4), J. ellyptica (column 5), M. fallax (column 6), M. albicans (column 7), M. sellowiana (column 8), S. barbatiman (column 9) and T. stenocarpa (column 10) - inhibited $100 \%$ of L. muta proteolytic activity (10 $\mathrm{gg} / \mathrm{mL}$ ) according to both venom:plant ratios evaluated (Figure 2B). Again, plant extracts or saline alone did not produce hemorrhagic lesions or interfere in the proteolytic assay (data not shown). 

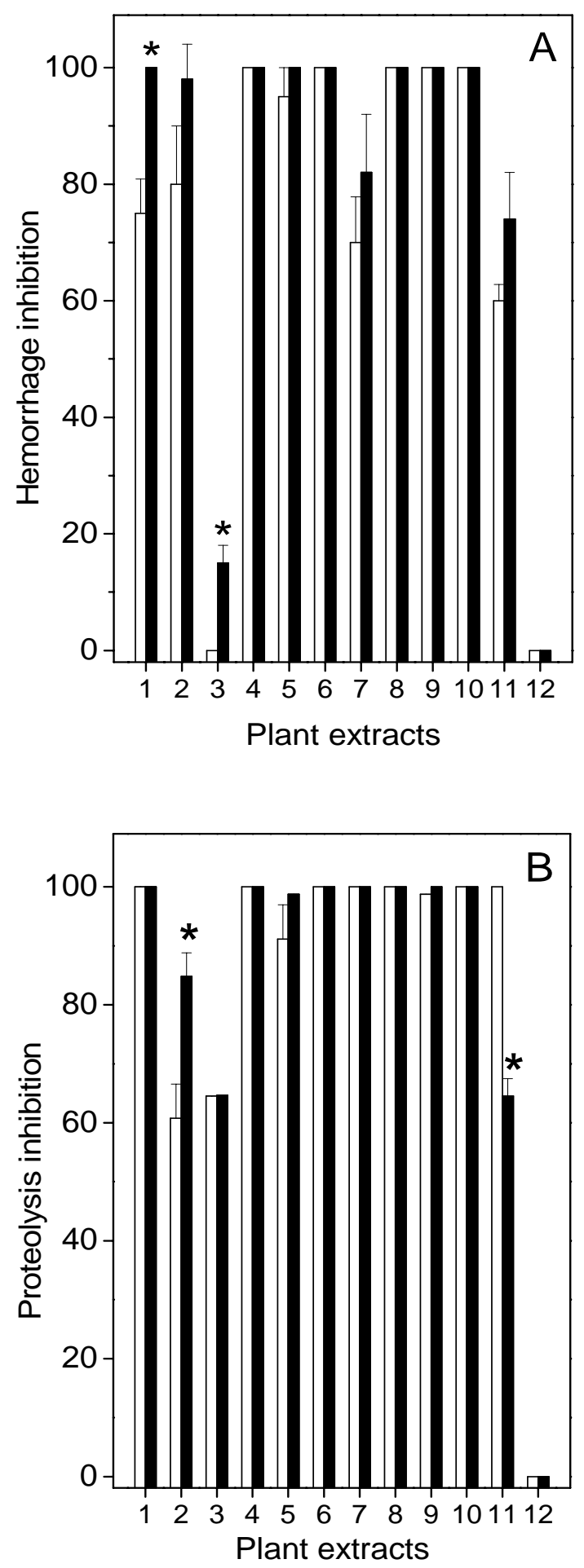

Figure 2. Inhibition of $L$. muta venom-induced hemorrhagic (Panel A) or proteolytic (Panel B) activities by plant extracts at 1:10 (white column) or 1:20 (black column) venom:plant ratio $(\mathrm{w} / \mathrm{w})$. Data are expressed as means $\pm \mathrm{SD}$ of four individual experiments $(n=4)$.

* Significance level $(p<0.05)$ when compared to the white column. 


\section{Inhibitory Profile of Plant Extracts}

Furthermore, we compared the inhibitory profile of plant extracts according to their indirect hemolytic (hemolysis), clotting, hemorrhagic and proteolytic biological activities (Table 1). As shown in Table 1, none of these activities was affected by $S$. saponaria. However, M. glomerata and J. ellyptica (stems) extracts were not able to completely inhibit any activity; but M. velutina, J.ellyptica (leaves) or C. sylvestris extracts fully inhibited at least one activity (clotting, proteolytic and proteolytic, respectively). On the other hand, the extracts of $M$. fallax (hemolysis and hemorrhagic), M. albicans (hemorrhagic and proteolytic), M. sellowiana (hemolysis and proteolytic), S. barbatiman (hemolysis, hemorrhagic and proteolytic) and $T$. stenocarpa (hemolysis, hemorrhagic and proteolytic), inhibited $100 \%$ of at least two of those activities. Also, it is worth highlighting that only the $S$. barbatiman extract fully abolished all of the activities assessed in this work (Table 1).

Table 1. Inhibitory percentage of plant extracts against $L$. muta snake venom's biological activities

\begin{tabular}{c|c|c|c|c}
\hline Extracts & Hemolysis $^{\text {a }}$ & Hemorrhagic $^{\text {b }}$ & Clotting $^{\text {c }}$ & Proteolytic $^{\text {d }}$ \\
\hline E. alba (roots) & 100 & 75 & 100 & 100 \\
\hline M. velutina (roots) & 86 & 80 & 100 & 60 \\
\hline M. glomerata (roots) & 21 & 0 & 15 & 64 \\
\hline J. ellyptica (leaves) & 44 & 0 & 20 & 100 \\
\hline J. ellyptica (stems) & 74 & 94 & 18 & 91 \\
\hline M. fallax (stems) & 100 & 100 & 33.3 & 100 \\
\hline M. albicans (stems) & 75 & 100 & 0 & 100 \\
\hline M. sellowiana (n.d.) & 100 & 71 & 0 & 100 \\
\hline S. barbatiman (roots) & 84 & 100 & 100 & 98 \\
\hline T. stenocarpa (roots) & 100 & 100 & 61 & 100 \\
\hline C. sylvestris (roots) & 10 & 61 & 18 & 100 \\
\hline S. saponaria (roots) & 0 & 0 & 0 & 0 \\
\hline
\end{tabular}

Plant extracts were preincubated with $L$. muta crude venom at 1:10 ratio (venom:plant, w/w) and then assayed for these activities. The values above are expressed as inhibition percentage (\%) of the venom amount able to produce: $70-80 \%$ hemolysis (MIHD) ${ }^{\mathbf{a}}$; hemorrhagic halo of $10 \mathrm{~mm}(\mathrm{MHD})^{\mathbf{b}}$; clot plasma in 60 seconds (MCD) ${ }^{c}$; produce a variation of $0.2 \mathrm{~nm}$ at $420 \mathrm{~nm}(\mathrm{MPD})^{\mathrm{d}}$.

n.d.: not determined. 


\section{DISCUSSION}

Given the high incidence of accidents caused by Bothrops and Crotalus species, data from the literature have focused much attention on them (10). But, although the accidents caused by L. muta snake venom are rare, they also represent a medical problem in Brazil, especially because of the high lethality index (1.0\%) when compared to approximately $0.3 \%$ for the Bothrops genus (2).

Envenomation by L. muta promotes a wide range of symptoms including nociception, edema and muscle necrosis, as well as neurotoxic, hemorrhagic, hemolytic and blood clotting disorders. These effects are related to the presence of phospholipase $\mathrm{A}_{2}$ enzymes, serino- and metalloproteases, L-amino acid oxidases, nucleotidases and others. The pathophysiological alterations may cause victims to die. To counteract those systemic and local effects of venoms, an antiserum is used as treatment.

According to the Brazilian Health Ministry and World Health Organization (11) guidelines, the antiophidic serum is produced by the following three public institutes in Brazil: the Butantan Institute in São Paulo city, São Paulo state; Ezequiel Dias Foundation in Belo Horizonte city, Minas Gerais state; and the Vital Brasil Institute, in Niterói city, Rio de Janeiro state; and then distributed free of charge to hospitals. As far as we know, this treatment is not efficient enough to neutralize local effects, thus contributing to high morbidity indexes observed in Brazil $(2,12-15)$.

Indeed, antisera possess some disadvantages such as side effects in victims, poor availability in distant areas, delays in administration, need for refrigeration, high cost and low efficacy $(3,10)$. Furthermore, snake venoms have both inter- and intraspecific variation in composition that, in turn, may affect antivenom neutralization ability (16). Because of these factors, alternative treatments for snakebite are under investigation and plant extracts constitute a rich source of molecules with several pharmacological properties $(4,17,18)$.

In several countries, plants have been used by indigenous groups and in folk medicine against snake bite envenomation. However, in most of the cases, scientific validation of their antiophidian properties is needed. As far as we know, there are many examples of medicinal plants in folk medicine and it is believed that $80 \%$ of the world population uses plants as the first-line treatment in cases of envenomation (18). Although the action mechanism remains unknown, several reports have shown that plant-derived compounds including rosmarinic acid, quercetin, aristolochic acid 
pterocarpans and terpenoids and crude extracts are able to neutralize toxic snake venom effects $(17,19-23)$.

In the present experiment we demonstrated for the first time the ability of different aqueous plant extracts to neutralize biological effects of $L$. muta snake venom, due to the scarcity of data on the use of plants to neutralize its venom. All of the plant extracts tested in this work inhibited at least one biological activity, except for $S$. saponaria that failed to neutralize any activity. The biological activities evaluated herein are relevant to envenomation symptoms such as necrosis, hemolysis, hemorrhage, inflammation, edema and pain, which obviously may contribute to victim fatalities. Therefore, vegetal extracts appears as an alternative treatment against local damage to complement the serum therapy or may be useful as prototypes for designing new antiophidian molecules to improve the current treatment used for $L$. muta bites.

\section{ACKNOWLEDGMENTS}

This work was supported by the State of Rio de Janeiro Research Foundation (FAPERJ), the State of São Paulo Research Foundation (FAPESP), the National Council for Scientific and Technological Development (CNPq), the Coordination for the Improvement of Higher Education Personnel (CAPES) and the International Foundation for Science (IFS grant F/4571-1).

\section{REFERENCES}

1. de Paula RC, Castro HC, Rodrigues CR, Melo PA, Fuly AL. Structural and pharmacological features of phospholipases $A_{2}$ from snake venoms. Protein Pept Lett. 2009;16(8):899-07.

2. Ministério da Saúde do Brasil. Fundação Nacional de Saúde. Manual de diagnóstico e tratamento de acidentes por animais peçonhentos. 2nd ed. Brasília: FUNASA; 2001. 120 p.

3. Gutiérrez JM, Fan HW, Silvera CL, Angulo Y. Stability, distribution and use of antivenoms for snakebite envenomation in Latin America: report of a workshop. Toxicon. 2009;53(6):625-30.

4. Maiorano VA, Marcussi S, Daher MA, Oliveira CZ, Couto LB, Gomes OA, et al. Antiophidian properties of the aqueous extract of Mikania glomerata. $\mathrm{J}$ Ethnopharmacol. 2005;102(3):364-70. 
5. Fuly AL, Machado OL, Alves EW, Carlini CR. Mechanism of inhibitory action on platelet activation of a phospholipase $\mathrm{A}_{2}$ isolated from Lachesis muta (Bushmaster) snake venom. Thromb Haemost. 1997;78(5):1372-80.

6. Quick AJ. Hemostasis and blood coagulation. Science. 1973;182(4107):87.

7. Melo PA, do Nascimento MC, Mors WB, Suarez-Kurtz G. Inhibition of the myotoxic and hemorrhagic activities of crotalid venoms by Eclipta prostrata (Asteraceae) extracts and constituents. Toxicon. 1994;32(5):595-03.

8. Garcia ES, Guimarães JA, Prado JL. Purification and characterization of a sulfhydryl-dependent protease from Rhodnius prolixus midgut. Arch Biochem Biophys. 1978;188(2):315-22.

9. Fuly AL, Francischetti IM, Zingali RB, Carlini CR. Partial purification and some physicochemical properties of phospholipases $A_{2}$ from the venom of the bushmaster snake (Lachesis muta). Braz J Med Biol Res. 1993;26(5):459-63.

10. Cruz LS, Vargas R, Lopes AA. Snakebite envenomation and death in the developing world. Ethn Dis. 2009;19(1 Suppl 1):42-6.

11. WHO. Normes relatives aux immunsèrums d'origine animale. WHO Sér Rapp Tech. 1969;413(1)47-61.

12. da Silva JO, Fernandes RS, Ticli FK, Oliveira CZ, Mazzi MV, Franco JJ, et al. Triterpenoid saponins, new metalloprotease snake venom inhibitors isolated from Pentaclethra macroloba. Toxicon. 2007;50(2):283-91.

13. Gutiérrez JM, Rojas G, Lomonte B, Gene JA, Chaves F, Alvarado J, et al. Standardization of assays for testing the neutralizing ability of antivenoms. Toxicon. 1990;28(10):1127-29.

14. Zamunér SR, da Cruz-Hofling MA, Corrado AP, Hyslop S, Rodrigues-Simioni L. Comparison of the neurotoxic and myotoxic effects of Brazilian Bothrops venoms and their neutralization by commercial antivenom. Toxicon. 2004;44(3):259-71.

15. Gutiérrez JM, Lomonte B. Local tissue damage induced by Bothrops snake. Mem Inst But. 1989;51(1):211-23.

16. Queiroz GP, Pessoa LA, Portaro FC, Furtado M de F, Tambourgi DV. Interspecific variation in venom composition and toxicity of Brazilian snakes from Bothrops genus. Toxicon. 2008;52(8):842-51.

17. Soares AM, Ticli FK, Marcussi S, Lourenço MV, Januário AH, Sampaio SV, et al. Medicinal plants with inhibitory properties against snake venoms. Curr Med Chem. 2005;12(22):2625-41. 
18. Mors WB, Nascimento MC, Pereira BM, Pereira NA. Plant natural products active against snake bite: the molecular approach. Phytochemistry. 2000;55(6):627-42.

19. Ticli FK, Hage LIS, Cambraia RS, Pereira OS, Magro AJ, Fontes MRM, et al. Rosmarinic acid, a new snake venom phospholipase $A_{2}$ inhibitor from Cordia verbenacea (Boraginaceae): antiserum action potentiation and molecular interaction. Toxicon. 2005;46(3):318-27.

20. Nishijima CM, Rodrigues CM, Silva MA, Lopes-Ferreira M, Vilegas W, HirumaLima CA. Anti-hemorrhagic activity of four Brazilian vegetable species against Bothrops jararaca venom. Molecules. 2009;14(3):1072-80.

21. Lindahl $M$, Tagesson $C$. Selective inhibition of group II phospholipase $A_{2}$ by quercetin. Inflammation. 1993;17(5):573-82.

22. Girish KS, Kemparaju K. Inhibition of Naja naja venom hyaluronidase by plantderived bioactive components and polysaccharides. Biochemistry (Mosc). 2005;70(8):948-52.

23. da Silva AJ, Coelho AL, Simas AB, Moraes RA, Pinheiro DA, Fernandes FF, et al. Synthesis and pharmacological evaluation of prenylated and benzylated pterocarpans against snake venom. Bioorg Med Chem Lett. 2004;14(2):431-5. 